\title{
Anatomia foliar deMaytenus Mol. emend Mol. (Celastraceae), ocorrente no Estado do Rio de Janeiro, Brasil ${ }^{1}$
}

\author{
Ana Joffily ${ }^{2,3}$ e Ricardo Cardoso Vieira ${ }^{2}$
}

Recebido em 08/06/2004. Aceito em 07/01/2005

\begin{abstract}
RESUMO - (Anatomia foliar de Maytenus Mol. emend Mol. (Celastraceae), ocorrente no Estado do Rio de Janeiro, Brasil). Este trabalho aborda o estudo anatômico de cinco espécies do gênero Maytenus Mol. emend. Mol. (Celastraceae). O gênero é o maior da família, e está representado no Brasil por aproximadamente 80 espécies. Maytenus é um gênero polifilético, necessitando de trabalhos adicionais para nova circunscrição. Maytenus ardisiaefolia Reiss., M. brasiliensis Mart., M. cestrifolia Reiss., M. communis Reiss. e M. obtusifolia Mart. são de difícil identificação, devido à semelhança dos verticilos reprodutivos, e pela variação na forma e no tamanho das folhas. As estruturas anatômicas observadas nas diversas partes da folha mostraram-se muito semelhantes nas espécies estudadas, sendo de valor taxonômico e de provável importância filogenética para o gênero Maytenus. A organização da epiderme e estratos subepidérmicos em M. obtusifolia demonstrou ser caráter diagnóstico importante na comparação com $M$. ardisiaefolia, e a ocorrência de cristais aciculares nas células epidérmicas de $M$. communis e de $M$. ardisiaefolia, que as separam de $M$. cestrifolia, que não apresenta cristais, apontaram a anatomia como importante ferramenta a ser explorada nos estudos taxonômicos das demais espécies do gênero. A observação e descrição das verrugas suberosas na epiderme da lâmina foliar poderá contribuir para a taxonomia das Celastraceae.
\end{abstract}

Palavras-chave: Celastraceae, Maytenus, anatomia foliar, verrugas suberosas

\begin{abstract}
Leaf anatomy of the Maytenus Mol. emend Mol. (Celastraceae) in Rio de Janeiro State, Brazil). This paper describes anatomical approaches to study the Genus Maytenus Mol. Emnd. Mol. (Celastraceae). The genus is the largest in the family Celastraceae, and in Brazil is represented by approximately 80 species. Maytenus is a polyphyletic genus and additional research is required to better understand its taxonomy. Maytenus ardisiaefolia Reiss., M. brasiliensis Mart., M. cestrifolia Reiss., M. communis Reiss. and M. obtusifolia Mart. are difficult to identify because of similarities in their reproductive structures and variations in the size and shape of their leaves. The anatomical structures observed within various parts of the leaves were similar in all the species studied and, as such, are of taxonomic and probably phylogenteic value for the genus Maytenus. The organisation of the epidermis and subepidermal layers in M. obtusifolia proved to be an important diagnostic character in comparison with M. ardisiaefolia. Similarly, the occurrence of acicular crystals in epidermal cells of M. communis and M. ardisiaefolia separates $M$. cestrifolia where crystals were not seen. These results highlight the role of anatomy as an important tool to be exploited in taxonomic studies of other species within the genus Maytenus. The observation and description of cork warts in the epidermis of the leaf blade could contribute to Celastraceae taxonomy.
\end{abstract}

Key words : Celastraceae, Maytenus, leaf anatomy, cork wart

\section{Introdução}

O gênero Maytenus é o maior da família Celastraceae e está inserido na subfamília Celastroideae. Atualmente são reconhecidas cerca de 80 espécies distribuídas por todo território brasileiro (Carvalho-Okano 2005). No gênero os órgãos vegetativos são historicamente os principais caracteres utilizados na taxonomia por Reissek (1861), Loesener (1942), Handro (1968), Sebsebe (1985), CarvalhoOkano (2005; 1998), Pirani \& Carvalho-Okano (1999), uma vez que as flores apresentam características mais conservativas e úteis na determinação dos táxons superiores, tais como o reconhecimento de famílias e mesmo de gêneros, porém apresentam-se inconsistentes para as categorias infragenéricas (Cronquist 1988).

Maytenus ardisiaefolia Reiss., M. brasiliensis Mart., M. cestrifolia Reiss., M. communis Reiss. e M. obtusifolia Mart. são espécies de difícil circunscrição, acarretando freqüentes identificações dúbias. Estes são os únicos representantes brasileiros do gênero que possuem um conjunto de características em comum: ramos glabros, não lenticelados, cilíndricos

\footnotetext{
Parte da Dissertação de Mestrado do primeiro Autor

2 Universidade Federal do Rio de Janeiro, Departamento de Botânica, Instituto de Biologia, Centro de Ciências da Saúde, BlocoA, Laboratório de Morfologia Vegetal, Av. Brigadeiro Trompowsky s.n., CEP 21941-590, Ilha do Fundão, RJ, Brasil

3 Autor para correspondência: anajoffily@ hotmail.com.br
} 
à achatados, às vezes com projeções aliformes e folhas inermes glabras de bordo inteiro ou raramente crenados no terço superior. Entretanto foram colocadas em diferentes seções por Loesener (1942), que utilizou para distinguí-las o tamanho e o número de flores da inflorescência, o tamanho e a consistência do limbo foliar. Contudo, estes caracteres ainda se mostram variados e graduais, fazendo com que os limites específicos sejam tênues e imprecisos, uma vez que as características florais destas espécies apresentamse muito semelhantes e as folhas têm-se mostrado insuficientes quando utilizadas isoladamente para quase todos os gêneros da família (Hou 1955).

Ressalta-se ainda que os estudos taxonômicos em Maytenus basearam-se até agora, principalmente, em espécimes herborizados, em que muitos caracteres se perdem ou são danificados. Este fato acentua ainda mais a sobreposição das características utilizadas na definição das espécies, dificultando a identificação das mesmas e muitas vezes mostrando-se insatisfatório para a identificação do material fresco.

Os tradicionais métodos de estudo de plantas herborizadas, cuja morfologia externa é utilizada como principal ferramenta para a delimitação dos táxons, são muitas vezes responsáveis por inúmeros problemas taxonômicos não solucionados (Metcalfe \& Chalk 1979), principalmente porque estes caracteres são mais acessíveis, tornando-se fonte de dados para o reconhecimento das espécies e para a análise de suas relações evolutivas.

Embora não sejam tão acessíveis quanto à morfologia externa, a pesquisa moderna tem dedicado boa parte de seus estudos em busca de novos caracteres para auxiliar na taxonomia (Mayr 1989). Outras fontes de análise têm-se mostrado de extrema importância nessas relações, tais como a anatomia, os marcadores moleculares, a ecologia, a biologia reprodutiva e a de polinização, assim como a biogeografia e outras (Judd et al. 1999).

A comparação anatômica tem provado ser útil em alguns dos mais difíceis estudos taxonômicos (Carlquist 1961), porém é necessário entender a variação dos caracteres dentro de um indivíduo, espécie ou grupo de táxons relacionados, que podem ser qualitativos ou quantitativos. As folhas são órgãos altamente variáveis e a variação pode ser específica para espécies, gênero ou famílias. Numerosos caracteres anatômicos dentro da folha, como características da epiderme, inclusões minerais e estruturas secretoras têm provado ser de valor sistemático em diferentes linhagens (Dickison 2000).
Poucos trabalhos utilizando anatomia foram realizados como subsídio à taxonomia da subfamília Celastreoideae, estando essa apenas retratada nos trabalhos de Solereder (1908), den Hartog \& Baas (1978) e Metcalfe \& Chalk (1979). Escassos foram os trabalhos que trataram a anatomia de Maytenus individualmente. Sebsebe (1985) ao revisar as espécies de Maytenus do Noroeste da África e Ásia tropical, apresentou a anatomia do pecíolo de seis espécies. Ciqiu et al. (1986) estudaram a anatomia de 17 espécies e uma variedade da Ásia. Müller (1995) analisou a anatomia de uma espécie e uma variedade da Nova Caledônia (Pacífico) e van Wyk \& Archer (1987) estudaram a anatomia foliar de uma espécie africana.

Estudos anatômicos para as espécies brasileiras de Maytenus são raros, sendo apenas conhecidas as contribuições de Machado (1945) e P.M. Mendonça (dados não publicados). Na sua totalidade, os trabalhos existentes são de cunho fitoquímico, estando, principalmente, direcionados para M. ilicifolia Mart. ex. Reiss., M. aquifolium Mart. e M. robusta Reiss. (Niero et al. 2001; Leite et al. 2001; Mossi et al. 2004).

A análise anatômica realizada nas folhas das espécies Maytenus ardisiaefolia, M. brasiliensis, $M$. cestrifolia, M. communis e M. obtusifolia objetivam reconhecer um padrão da anatomia foliar, com intuito de contribuir com a taxonomia das espécies.

\section{Material e métodos}

As folhas completamente expandidas foram coletadas no 5-7 nó e fixadas em FPA (Ruzin 1999), desidratadas em série etílica, emblocadas em parafina (Sass 1951). Os cortes (11-13 $\mu \mathrm{m}$ espess.), no plano transversal, foram obtidos com auxílio de micrótomo rotativo e corados com Azul de Astra - Fucsina básica (Roeser 1962). Os cortes seriados foram realizados em toda a extensão do pecíolo e na nervura principal, região intercostal e bordo do terço mediano da lâmina foliar.

A epiderme foi dissociada pelo método de Jeffrey (Johansen 1940). A determinação do número de estômatos por unidade de área $\left(\mathrm{mm}^{2}\right)$ foi realizada pela projeção de um campo correspondente a um quadrado de $1 \mathrm{~mm}$ lado, calculando se a média aritmética de 30 campos. A classificação dos tipos de estômatos seguiu den Hartog \& Baas (1978).

Para alguns testes histoquímicos, utilizou-se cortes à mão livre de material recém-coletado, que posteriormente foram submetidos aos reagentes específicos. Assim, a cutícula e paredes suberizadas 
foram reconhecidas pelo Sudan IV, o amido pelo lugol (Johansen 1940) e a lignina pela floroglucina (Speer 1987). As substâncias fenólicas foram identificadas com os testes de cloreto férrico $10 \%$ com carbonato de sódio (Johansen 1940). Os cristais de oxalato de cálcio foram reconhecidos pela solubilidade em ácido clorídrico (Strasburger 1893).

A confecção dos desenhos foi realizada com auxílio de câmara-clara acoplada ao microscópio binocular ZEISS, sendo as escalas projetadas com a mesma combinação ótica. As fotomicrografias foram obtidas em um microscópio III da marca ZEISS.

Para as observações da rede de nervuras, as folhas foram diafanizadas de acordo com as recomendações de Strittmater (1973) e o padrão de venação foi classificado segundo Hickey (1974). Na descrição da morfologia da lâmina foliar utilizou-se o trabalho de Rizzini (1960/1961). Para diferenciar a forma da base e do ápice foi empregado o ângulo de abertura, sendo utilizada a nomenclatura obtusa $\left(\geq 90^{\circ}\right)$, aguda $\left(>60^{\circ}<90^{\circ}\right)$ e acuminada $\left(\leq 60^{\circ}\right)$.

Material examinado: Maytenus ardisiaefolia BRASIL. Rio de Janeiro: Rio de Janeiro, Parque Nacional da Tijuca, caminho para a Cachoeira das Almas, 21/X/2000, fl., A. Joffily 16 (R); idem, 21/X/2000, fl., A. Joffily 17 (RFA); idem, 21/X/2000, fl., A. Joffily 18 (RFA). Maytenus brasiliensis Magé, estrada do Matão, 170 msm, 12/II/2001, fr., $A$. Quinet 24/71 (RFA). Rio Janeiro, Horto do JBRJ, 5/VII/2001, fr., R. Marquete 3023 (RB). Maytenus cestrifolia - Rio de Janeiro, estrada da Vista Chinesa, Reserva Florestal da FEEMA, 10/I/2001, fl., A. Joffily 21 (R); idem, 10/I/2001, fl., A. Joffily 22 (RFA). Maytenus communis - Rio de Janeiro, Parque Nacional da Tijuca, caminho para a Cachoeira das Almas, 21/X/2000, fl., A. Joffily 20 (R), idem, 13/VIII/2001, fl., A. Joffily 30 (RFA); Pedra do Marinheiro, 1/VIII/2001, fr., A. Joffily 28 (RB). Maytenus obtusifolia - Campos dos Goitacazes, Restinga de Iquipari, 13/XI/1999, A. Joffily 15 et C.H.R. de Paula (RB). Rio de Janeiro, APA de Grumari, início da restinga, 18/XII/1997, fr, J.M.A. Braga 4545 et al. (RUSU); idem, 17/XI/2000, fr., J.M.A. Braga 6460 et al. (R, RB).

\section{Resultados}

Morfologia externa - As folhas são glabras e de filotaxia alterna. As formas da lâmina foliar das espécies variam de oblongo-lanceoladas à lanceoladas (Fig. 1a-c; 2). Contudo em M. obtusifolia podem ser obovada, orbicular, a oblongo-lanceolada (Fig. 1d-f). A base apresenta forma aguda para todas as espécies (Fig. 1a-d; 2), exceto em M. obtusifolia que ocorre a predominância da forma obtusa (Fig. 1e-f).

Em relação ao ápice, são observadas as formas aguda à acuminada em $M$. cestrifolia, M. communis, M. ardisiaefolia e M. brasiliensis (Fig. 1a-c; 2). Em M. obtusifolia a forma obtusa é a mais expressiva (Fig. 1e-f). Nas espécies estudadas, o bordo apresentase inteiro em toda a sua extensão ou, raramente, crenado no terço superior (Fig. 1, 2). O padrão de venação é do tipo camptódromo-broquidódromo. As nervuras secundárias encaminham-se em direção ao bordo formando arcos (Fig. 1b, e; 2c, f, h). Em todas as espécies as aréolas formam um padrão constante, porém sem apresentar orientação definida. Quanto ao formato, predomina o retangular, podendo apresentar terminações simples, lineares e curvas ou 2-3 ramificadas. A nervura mediana é proeminente apenas na face abaxial, ao contrário das nervuras secundárias que não são proeminentes.

Anatomia - Pecíolo - As espécies de Maytenus amostradas, no plano transversal, apresentam o pecíolo com o formato plano convexo ou levemente côncavoconvexo, em toda sua extensão. Duas projeções laterais são observadas na face adaxial, tornando-se mais evidentes em direção a região distal (Fig. 3-6). A epiderme é unisseriada, glabra e dotada de cutícula delgada e lisa (Fig. 6-8). O colênquima do tipo angular é encontrado subjacente a epiderme, em toda a extensão do pecíolo exceto nas projeções da região mediana e distal onde encontra-se parênquima fundamental. O parênquima cortical apresenta células com paredes delgadas, e pequenos espaços intercelulares (Fig. 6-8). Em todas as espécies foram observados idioblastos cristalíferos com cristais do tipo prismático (identificados pela solubilidade em ácido clorídrico), idioblastos encerrando compostos fenólicos (identificados pelo teste de cloreto férrico $10 \% \mathrm{com}$ carbonato de sódio) (Fig. 7) e braquiesclereides isodiamétricos (Fig. 8) dispersos pelo córtex. As espécies estudadas apresentam um feixe cilíndrico em toda a extensão do pecíolo com grupos de fibras perivasculares ocorrendo junto ao sistema vascular (Fig. 3-6 e 9). No floema, os elementos de transporte e células companheiras ocorrem em grupos, separados por células de parênquima que se destacam pelo tamanho e/ou compostos fenólicos. O xilema está constituído por elementos de proto e metaxilema, dispostos em séries radiais, separados por células parenquimáticas (Fig. 6 e 9). 
Anatomia - Lâmina foliar - As faces adaxial e abaxial da epiderme são glabras, constituídas de células com formato poligonal, e paredes anticlinais delgadas, retas ou levemente curvas (Fig 10-13). Cristais do tipo acicular são encontrados em ambas as faces de $M$. ardisiaefolia, $M$. brasiliensis, $M$. communis e M. obtusifolia (Fig. 10), com exceção de M. cestrifolia, que não apresentou cristais (Fig. 11). Em vista frontal observam-se verrugas suberosas, que são caracterizadas pela suberização de uma ou mais células formando uma estrutura que quando desenvolvida apresenta um arranjo concêntrico, conseqüente das divisões tangenciais sofridas pelas células periféricas que mostram-se dispostas radialmente (Fig. 12). Algumas verrugas suberosas apresentaram perfurações atravessando a lâmina foliar. Nas faces adaxial e abaxial, ocorrem verrugas originadas a partir de células ordinárias da epiderme (Fig. 12). Na face abaxial ocorrem verrugas oriundas da modificação do complexo estomático (Fig. 13).

As folhas são hipoestomáticas, com estômatos distribuídos ao longo da lâmina foliar, inclusive sob a nervura principal. Os tipos observados são laterocítico e ciclocítico, com predominância do primeiro (Fig. 11).
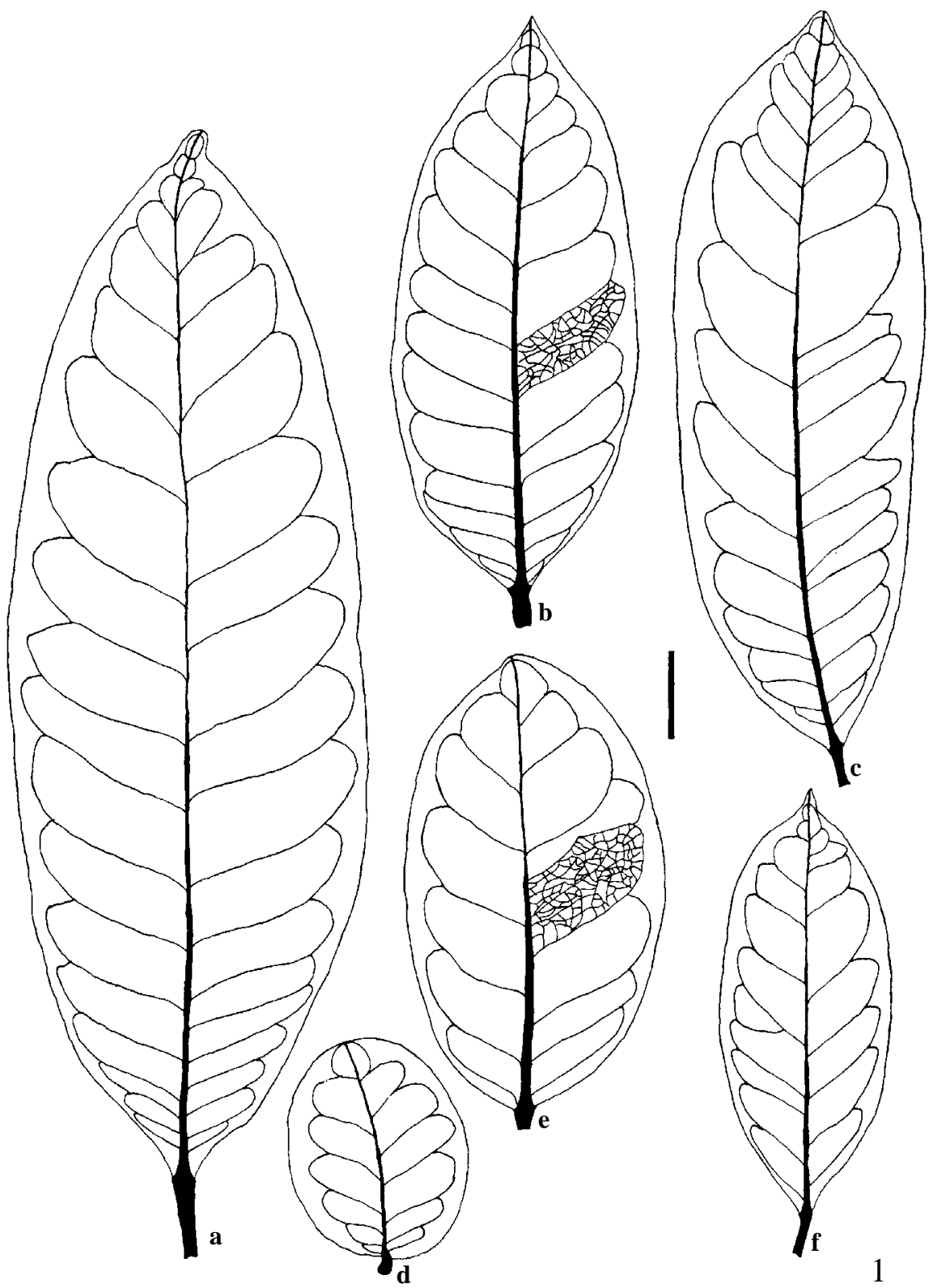

Figuras 1. Aspecto geral da variação morfológica das folhas, com padrão de venação do tipo camptódromo-braquidódromo em Maytenus ardisiaefolia Reiss. (a-c) e M. obtusifolia Mart. (d-f) (barra $=2 \mathrm{~cm}$ ). 
Maytenus ardisiaefolia apresenta a maior densidade de estômatos $\left(665\right.$ est $\left./ \mathrm{mm}^{2}\right)$, seguida de M. brasiliensis com (567 est $\left./ \mathrm{mm}^{2}\right)$, M. communis (453 est $\left./ \mathrm{mm}^{2}\right)$, M. obtusifolia $\left(457 \mathrm{est} / \mathrm{mm}^{2}\right)$ e M. cestrifolia $\left(288 \mathrm{est} / \mathrm{mm}^{2}\right)$. Seções no plano transversal mostram que a epiderme é uniestratificada, recoberta por cutícula delgada em todas as espécies (Fig. 14 e 15). Maytenus obtusifolia apresenta na face adaxial duas camadas subepidérmicas de maior dimensão, sendo que a última pode conter poucos cloroplastos (Fig. 16). O mesofilo é dorsiventral, variando apenas no número de camadas do parênquima clorofiliano (Fig. 14-16). O parênquima paliçadico possui 1 (raro 2) camada em M. communis (Fig. 15) e 2 (raro 3) camadas nas demais espécies (Fig. 14 e 16). O parênquima lacunoso apresenta 8-9 camadas em M. obtusifolia e 7-8 camadas em todas as espécies. Em $M$. ardisiaefolia e M. obtusifolia é observadas a presença braquiesclereídes, semelhantes aos do pecíolo, isolados ou em grupos, dispersos no parênquima clorofiliano. Contudo no mesofilo de M. obtusifolia ocorrem também braquiesclereídes com formato irregular, dotado de pequenas ramificações e esclereídes alongados caracterizando o tipo fusiforme
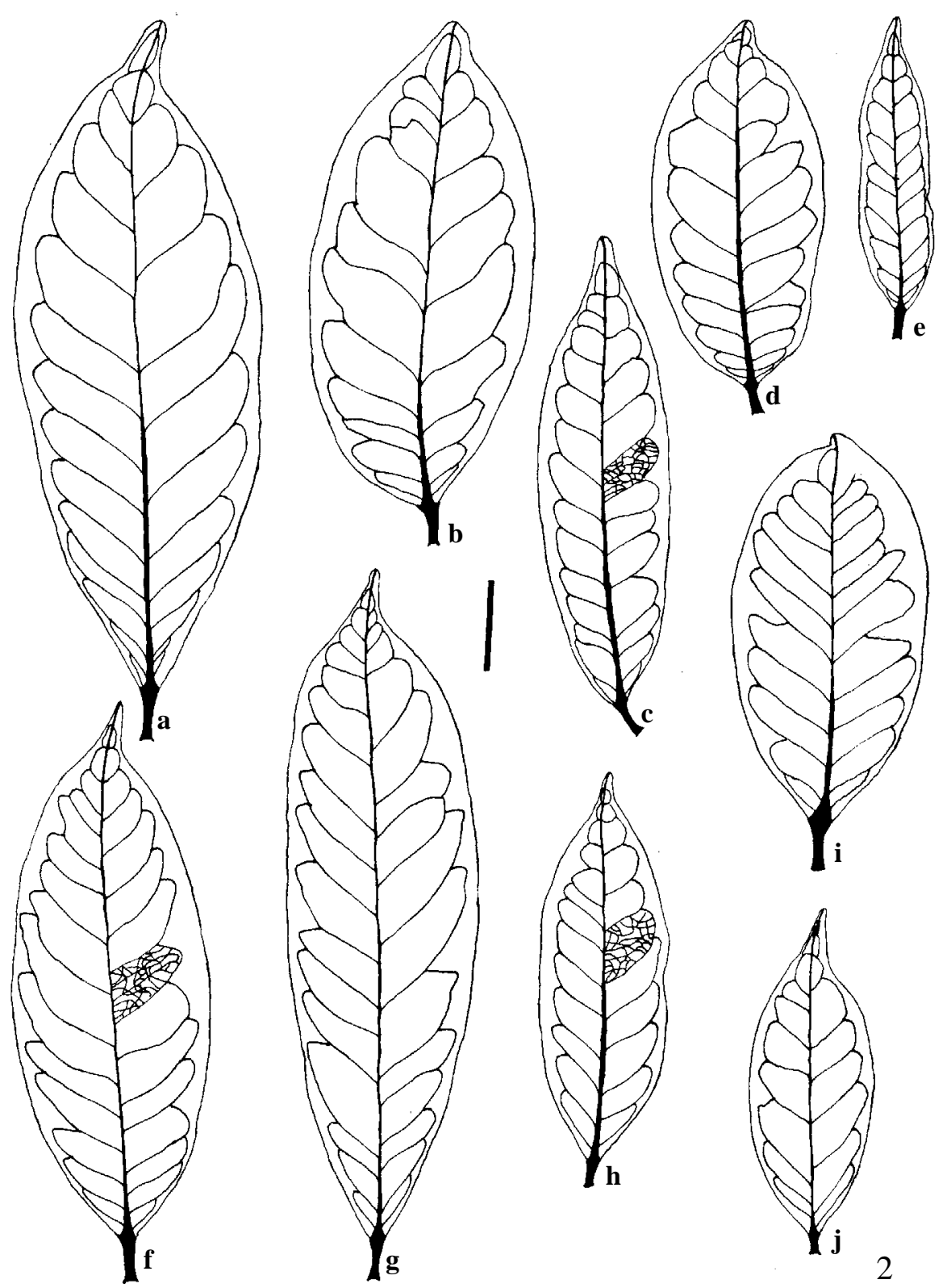

Figuras 2. Aspecto geral da variação morfológica das folhas, com padrão de venação do tipo camptódromo-braquidódromo em Maytenus communis Reiss. (a-e), M. cestrifolia Reiss. (f-g) e M. brasiliensis Mart. (h-i) (barra $=2 \mathrm{~cm}$ ). 
curto. Nas demais espécies, tais células não foram observadas. Idioblastos encerrando compostos fenólicos distribuem-se pelo parênquima clorofiliano, principalmente nas camadas próximas às faces adaxial e abaxial da epiderme de todas as espécies (Fig 14-16). $\mathrm{O}$ bordo apresenta-se fletido em direção a face abaxial.
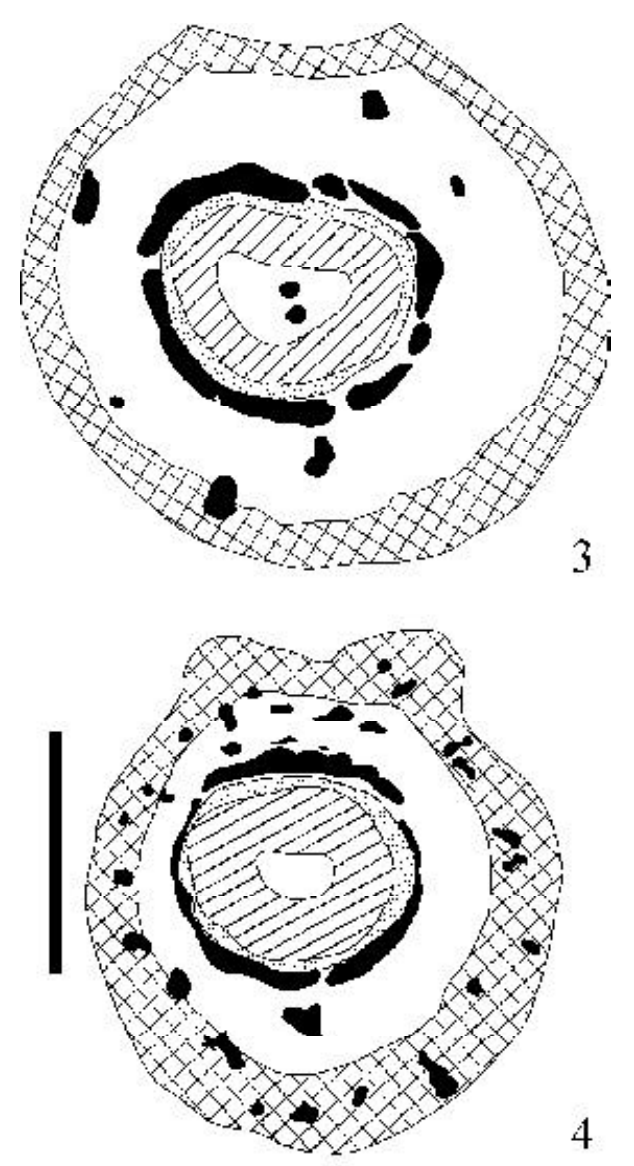

4

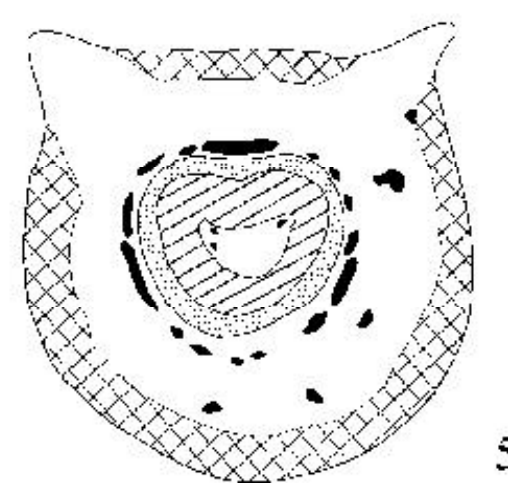

Figuras 3-5. Esquema evidenciando o feixe vascular cilíndrico do pecíolo, no plano transversal. 3. Região proximal em Maytenus ardisiaefolia Reiss. 4. Região mediana em M. cestrifolia Reiss. 5. Região distal em M. communis Reiss. $\mathbf{\square}=$ Fibra e Esclereíde,

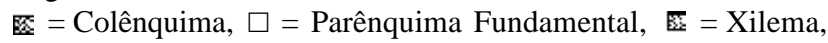
= Floema. (barra = $1 \mathrm{~mm}$ ).
Em M. ardisiaefolia, M. communis, M. brasiliensis e $M$. cestrifolia, a epiderme é uniestratificada com cutícula delgada (Fig. 17), ao contrário de M. obtusifolia, cuja epiderme apresenta-se constituída de 2 camadas de células, recoberta por cutícula espessa. Em todas as espécies estudadas, a extremidade do bordo é ocupada por elementos de parênquima clorofilado e células com compostos fenólicos. Esclereídes semelhantes aos do mesofilo foram observados em $M$. obtusifolia.

A nervura mediana, no plano transversal, apresenta a epiderme uniestratificada. Junto à epiderme adaxial, ocorrem 2-3 camadas de parênquima clorofiliano. Parênquima fundamental é observado subjacente ao parênquima clorofiliano (Fig. 18). No terço basal da lâmina foliar, o sistema vascular da nervura mediana apresenta-se fechado em todas as espécies, semelhante a disposição observada no pecíolo. Ao longo do terço médio, o sistema vascular abre gradativamente, originando um feixe maior em forma de arco voltado para a face abaxial e dois menores em direção à face adaxial (Fig. 18). Entretanto, diferentes conformações são observadas no processo de abertura do sistema vascular, que tem início na parte voltada à face adaxial, formando um arco com as extremidades próximas (Fig. 19). Contudo, aberturas laterais podem ocorrer formando um feixe maior em forma de arco voltado para a face abaxial e um menor voltado para a face adaxial (Fig. 20). No terço apical, o sistema vascular, está constituído por um único feixe sob a forma de arco (Fig. 21). Os tecidos condutores apresentam a mesma organização descrita para o pecíolo. Células encerrando compostos fenólicos distribuem-se no colênquima angular junto à face abaxial, parênquima clorofiliano e fundamental, assim como pelo parênquima do xilema e do floema (Fig. 18). Os feixes menores estão distribuídos ao longo da lâmina foliar, envolvidos por uma bainha de células parenquimáticas clorofiladas, podendo algumas apresentar compostos fenólicos.

\section{Discussão}

Os indivíduos de Maytenus ardisiaefolia, $M$. brasiliensis, M. cestrifolia e M. communis apresentaram predominância de características mesomórficas (Metcalfe \& Chalk 1979), condizentes com a fisionomia da Floresta da Tijuca. Por outro lado, algumas características diferenciadas observadas em M. obtusifolia estão, provavelmente, relacionadas com o grau de sombreamento e a disponibilidade de 

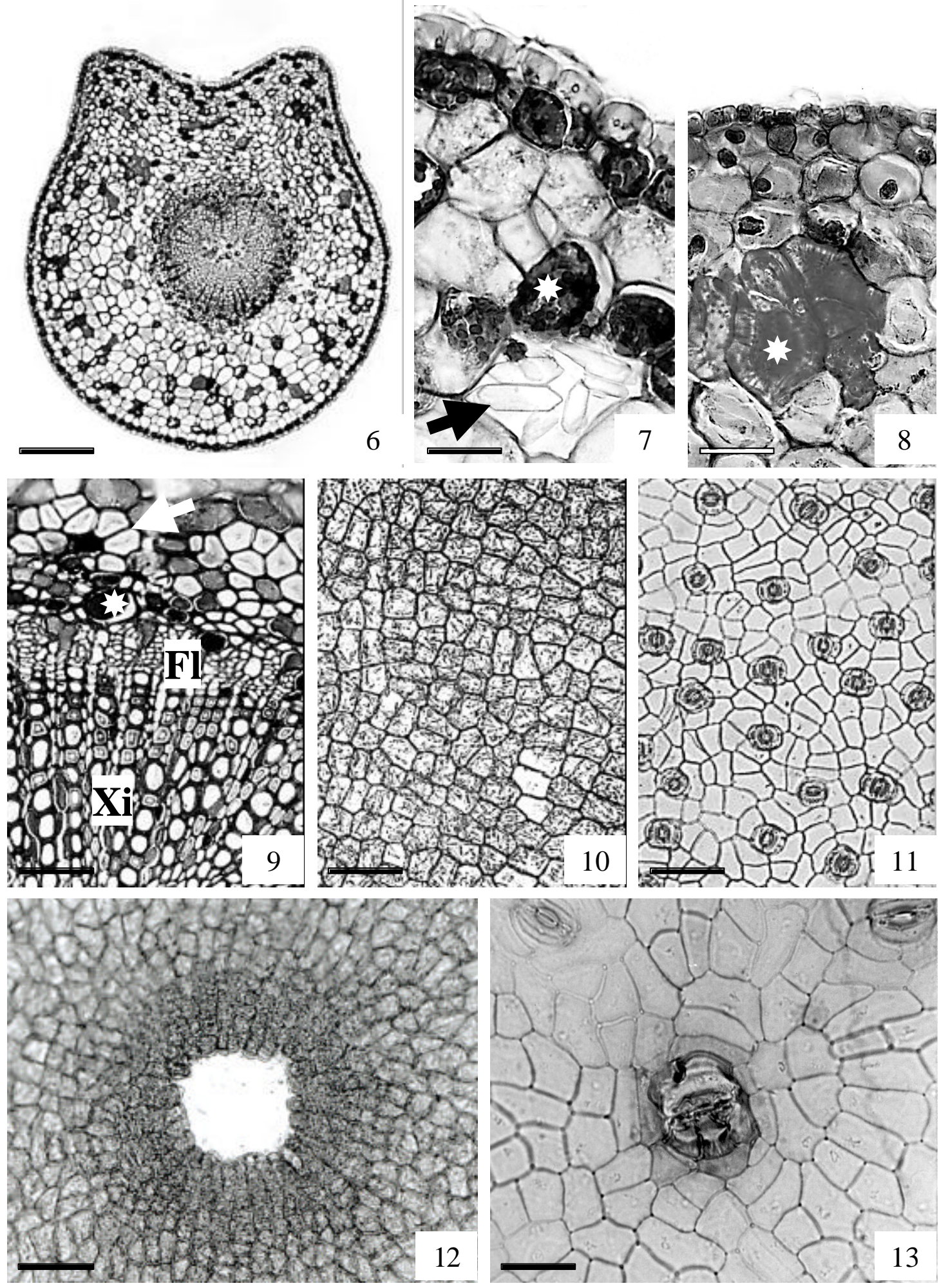

Figuras 6-9. Pecíolo. 6. Aspecto geral na região mediana de Maytenus cestrifolia Reiss., no plano transversal (barra $=300 \mu \mathrm{m})$. Figuras 7-8. Detalhe da epiderme e do córtex (barra $=50 \mu \mathrm{m})$. 7. Idioblastos com cristais prismáticos (seta) e compostos fenólicos (asterisco) em M. cestrifolia . 8. braquiesclereídes (asterisco) em M. brasiliensis Mart. 9. Detalhe do feixe vascular (Xi - xilema e Fl - floema), mostrando grupos de fibras perivasculares (seta) e células com compostos fenólicos (asterisco) em M. ardisiaefolia Reiss. (barra $=50 \mu \mathrm{m}$ ). Figuras 10-13. Epiderme em vista frontal da lâmina foliar. 10. Face adaxial com cristais aciculares em M. ardisiaefolia $($ barra $=50 \mu \mathrm{m}) .11$. Face abaxial de $M$. cestrifolia $($ barra $=50 \mu \mathrm{m}$ ). 12-13. Verrugas suberosas ('Cork Wart'). 12. Tipo ordinário na face adaxial de M. obtusifolia Mart. (barra $=50 \mu \mathrm{m})$. 13- Tipo estomático na face abaxial de $M$. cestrifolia (barra $=12 \mu \mathrm{m}$ ). 
água das restingas de Grumari e Iquipari (A.M. Argôlo, dados não publicados), que são menores do que os encontrados na floresta da Tijuca.

A extrema variedade na forma e no tamanho das folhas observadas nas espécies estudadas tem se mostrado também muito freqüente nas espécies dos mais diversos gêneros de Celastraceae, sendo comum encontrar duas ou três formas diferentes descritas para a mesma espécie, como observado em Lourteig \&
O’Donell (1955); Smith (1940); Hallé (1981; 1984); van Wyk \& Archer (1987); Archer (1992); Archer \& van Wyk (1997a; 1997b; 1998a; 1998b); Jordaan \& van Wyk (1999b). Entretanto, as características das folhas permanecem como um importante caráter taxonômico na circunscrição dos táxons subordinados ao gênero Maytenus, conforme utilizadas por Herter \& Legrand (1936), Cuatrecasas (1959) e Hammel (1997) e principalmente para as espécies brasileiras
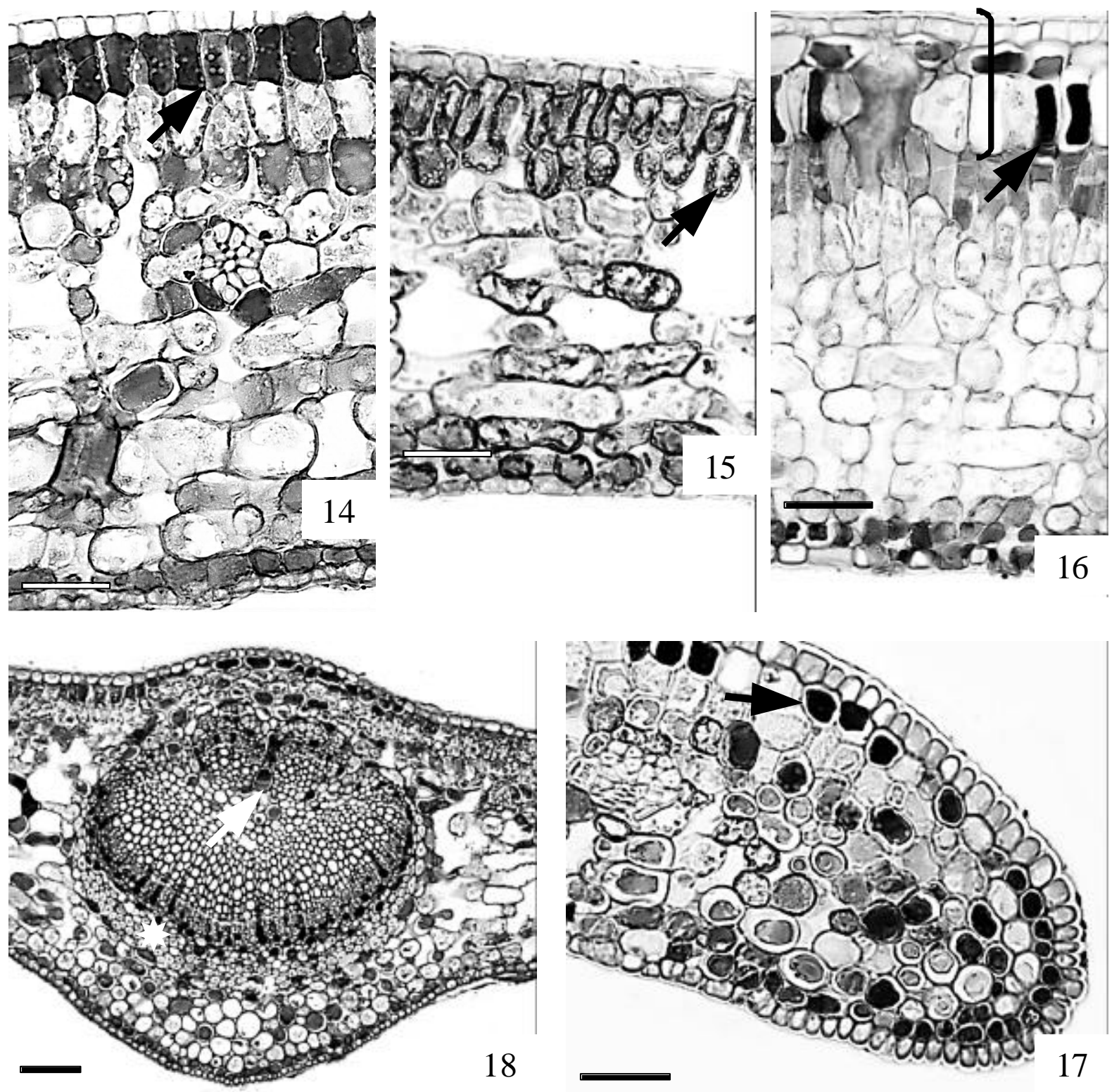

Figuras 14-18. Cortes transversais no terço médio da lâmina foliar. 14-16. Mesofilo dorsiventral evidenciando células com compostos fenólicos (seta) (barra = $50 \mu \mathrm{m})$. 14-15. Epiderme uniestratificada em Maytenus ardisiaefolia Reiss. (14) e M. communis Reiss. (15). 16. Epiderme e duas camadas subepidérmicas (colchete) em M. obtusifolia Mart. 17. sistema vascular da nervura mediana, evidenciando fibras perivasculares dispostas em grupos (asterisco) e idioblastos com compostos fenólicos entre os elementos vasculares (seta) em M. cestrifolia Reiss. (barra $=130 \mu \mathrm{m}$ ). 18. bordo onde pode ser observado parênquima clorofilado e idioblastos com compostos fenólicos (seta) em M. ardisiaefolia (barra $=300 \mu \mathrm{m}$ ). 
estudadas por Reissek (1861), Loesener (1892; 1942), Carvalho-Okano $(2005 ; 1998)$ e Pirani \& CarvalhoOkano (1999).

O bordo é reconhecidamente um importante caráter para a identificação das seções de Maytenus (Loesener 1942). Carvalho-Okano (2005) reconheceu apenas duas seções para o gênero. A seção Oxyphylla formada por espécies com acúleos no bordo foliar e a seção Maytenus caracterizada pelo bordo inteiro, serrilhado, dentilhado ou crenado. As cinco espécies estudadas estão subordinadas a seção Maytenus (senso Carvalho-Okano 2005).

As espécies estudadas apresentam o bordo inteiro em toda a sua extensão ou, raramente, crenado no terço superior. Sebsebe (1985) menciona que a variação das características do bordo apresentam-se confusas. $\mathrm{O}$ autor assinala que em M. forskaoliana Sebsebe e M. heterophylla (Eckl. \& Zeyh.) Robson, apesar da predominância do bordo inteiro, existem indivíduos com folhas nitidamente serrilhadas.

As espécies $M$. cestrifolia e M. ardisiaefolia foram classificadas por Carvalho-Okano (2005) como
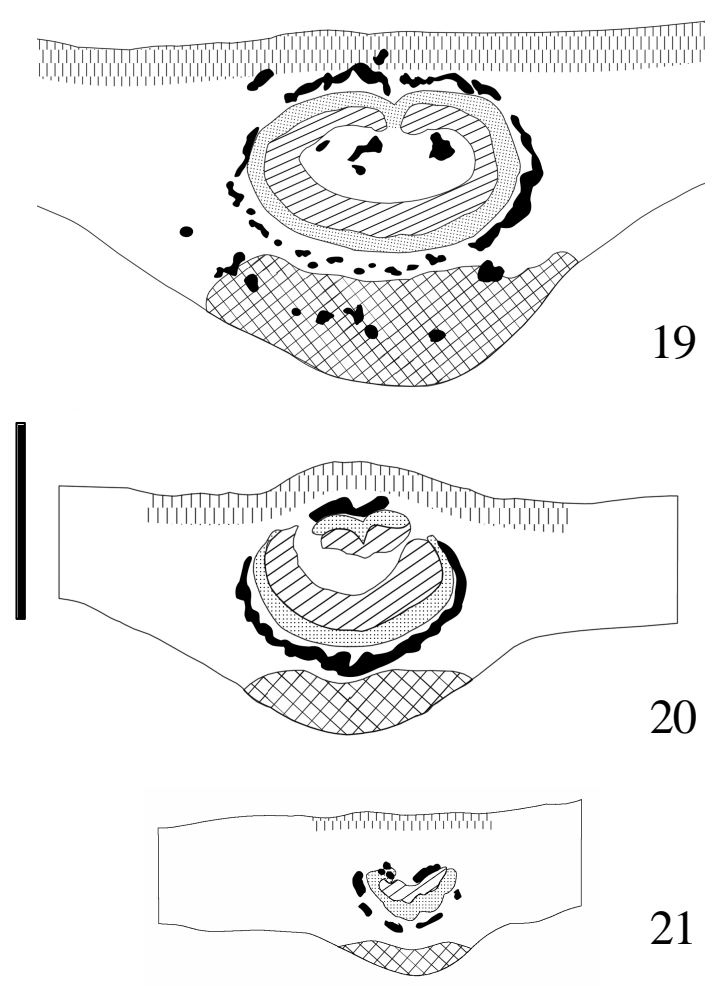

Figuras 19-21. Representações esquemáticas da nervura mediana. no plano transversal mostrando o padrão do sistema vascular. 19-20. Terço mediano. 19. Maytenus obtusifolia Mart. 20. M. brasiliensis Mart. 21. Terço apical em M. ardisiaefolia Reiss. - = Fibra e Esclereíde, $\mathbf{0}$ = Colênquima, $\square=$ Parênquima

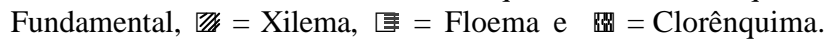
(barra $=500 \mu \mathrm{m})$. apresentando o bordo sempre inteiro, enquanto em M. communis, M. brasiliensis e M. obtusifolia ocorrem indivíduos intermediários, cujo bordo varia de inteiro a serrilhado ou crenado. Carvalho-Okano (2005) acrescenta que neste caso, o bordo constitui um bom caráter diagnóstico para a separação das espécies M. communis e M. cestrifolia. Contudo, a consulta de material herborizado associada à observação das espécies no campo, indicaram que a variação no bordo das folhas está presente em todas as espécies analisadas.

O padrão de venação do tipo camptódromobroquidódromo e a proeminência da nervura mediana, na face abaxial, mostraram-se constante nas espécies estudadas. Carvalho-Okano (2005) considerou a proeminência da nervura como um bom caráter para a identificação das espécies de Maytenus extraamazonicas. Contudo, ao analisar o material fresco verificou-se que este caráter não apresentou modificações significativas entre as espécies estudadas. Além disso, a proeminência das nervuras é acentuada no processo de herborização, mostrando se um caráter variável e pouco confiável.

O formato plano convexo ou levemente côncavoconvexo do pecíolo associado a presença de braquiesclereídes, idioblastos com compostos fenólicos e sistema vascular cilíndrico envolto por grupos de fibras perivasculares descrito para as espécies estudadas, são semelhantes às características observadas nos taxa brasileiros M. gonoclada Mart. e M. salicifolia Reiss. (P.M. Mendonça, dados não publicados) e nas africanas $M$. gracilipes subsp. arguta (Loes.) Sebsebe e M. senegalensis (Lam.) Exell (Sebsebe 1985). Apesar da pouca utilização do formato do pecíolo como caráter diagnostico, este mostrou-se um bom caráter uma vez que diferencia M. forskaoliana, procedente da Nova Caledônia (Pacífico), que apresenta o pecíolo com formato achatado (Müller 1995).

As características do sistema vascular do pecíolo das Angiospermas foram consideradas como significativas para a taxonomia por Howard (1979). Os caracteres observados no sistema vascular não apresentaram diferenças significativas para a taxonomia das espécies brasileiras de Maytenus estudadas até o momento, devido às semelhanças observadas por P.M. Mendonça (dados não publicados). Contudo, Müller (1995) classificou como aberto o feixe vascular do pecíolo de M. forskaoliana. A forma do feixe vascular do pecíolo é um importante caráter na determinação de Maytenus como um gênero 
polifilético, reforçando assim a necessidade de um estudo taxonômico para uma nova circunscrição do gênero (Jordaan \& van Wyk 1999a; 1999b; Simmons \& Hedin 1999; Simmons et al. 2001). Neste contexto, a semelhança observada nos caracteres do pecíolo, das espécies aqui estudadas, confirmam a proximidade entre elas e a provável monofilia das espécies de Maytenus do neotrópico.

A epiderme de $M$. ardisiaefolia, M. brasiliensis, M. communis e M. obtusifolia apresentaram cristais do tipo acicular, entretanto em $M$. cestrifolia não foram observados cristais. A presença e o tipo de cristal foram características importantes utilizadas por Ciqiu et al. (1986), que classificaram as epidermes das espécies asiáticas de Maytenus em quatro grupos: sem cristais, com cristais prismáticos, com drusas e com os dois tipos. A ocorrência de apenas um tipo de cristal nas Maytenus estudadas confirma a semelhança morfológica entre elas. A presença de cristais em $M$. ardisiaefolia e $M$. communis e a ausência em $M$. cestrifolia mostrou ser um caráter fundamental na identificação do material vegetativo, uma vez que, os ramos e a forma da lâmina foliar das três espécies são muito semelhantes, sendo muitas vezes impossível a identificação das mesmas. Concomitantemente, a facilidade de dissociação da epiderme em material herborizado viabiliza a utilização deste caráter pelos taxonomistas.

Em todas as espécies verificou-se, na epiderme da lâmina foliar, a ocorrência de verrugas suberosas nas faces adaxial e abaxial da epiderme. Verrugas suberosas ('Cork Wart') foram citadas para epiderme da lâmina foliar de diversas famílias por Solereder (1908) e Metcalfe \& Chalk (1950). Para Stace (1965), a presença de verrugas suberosas na lâmina foliar constitui um caráter taxonomico adicional importante, uma vez que esta estrutura, apesar de pouco abundante na natureza, é constante nas espécies onde ocorrem. Bass (1975) acredita que a utilização de verrugas suberosas como caráter diagnóstico e sistemático têm sido pouco aproveitado pelos taxonomistas, em função destes não conseguirem, muitas vezes, distinguir verrugas suberosas regulares de áreas traumáticas irregulares e suberizadas. Neste sentido, a determinação do padrão e dos tipos de verrugas ocorrentes em Maytenus poderão representar um caráter significativo na taxonomia e nas relações filogenéticas do gênero.

No plano transversal, $M$. ardisiaefolia, $M$. brasiliensis, $M$. cestrifolia e $M$. communis apresentaram a epiderme uniestratificada, apenas $M$. obtusifolia diferenciou-se das demais por apresentar dois estratos subepidérmicos. A presença de hipoderme é mencionada por Ciqiu et al. (1986), Müller (1995) e van Wyk \& Archer (1987) para várias espécies de Maytenus, porém nenhum deles indica ter realizado a ontogênese das folhas. Apesar da semelhança, para M. obtusifolia, adotou-se epiderme e estratos subepidérmicos, ao invés de hipoderme, uma vez que não foi realizada a ontogênese das folhas.

Ciqiu et al. (1986) observaram, nas espécies de Maytenus asiáticas, que o número de camadas da epiderme não variou nos indivíduos de diferentes ambientes, sendo assim, um caráter taxonômico confiável. Os indivíduos de $M$. obtusifolia, provenientes do subdossel de mata, apresentam características semelhantes às observadas em M. ardisiaefolia, tais como a forma das folhas e o maior comprimento dos frutos. A diferença entre as duas espécies dar-se-á pelo número de camadas da epiderme. Em M. obtusifolia, este caráter pode ser considerado confiável, pois o número de camadas da epiderme foi o mesmo nas folhas expostas a maior luminosidade e nas folhas coletadas na sombra.

Os estômatos observados do tipo laterocítico e ciclocítico, com predominância do primeiro, foram encontrados na face abaxial de todas as espécies, assim como as analisadas por Müller (1995) e P.M. Mendonça (dados não publicados). As classificações enquadramse nos tipos descritos por Pant \& Kidwai (1966) e den Hartog \& Baas (1978), para diferentes gêneros da família Celastraceae. A diferença no número de estômatos de $M$. ardisiaefolia em relação a $M$. cestrifolia não pode ser atribuída a fatores ambientais uma vez que as espécies vegetam em localidades próximas e similares.

A observação da nervura mediana, no terço basal, mediano e distal permitiu o estabelecimento do padrão do sistema vascular, e a semelhança deste padrão corroborou com a afinidade morfológica entre as espécies estudadas. Entretanto, o padrão do sistema vascular da nervura mediana poderá apresentar-se como um caráter taxonômico, ao analisar um número maior de espécies do gênero.

Metcalfe \& Chalk (1950) e Ciqiu et al. (1986) classificaram o feixe vascular da nervura mediana do gênero Maytenus como aberto ou fechado. Entretanto nenhum dos autores supracitados mencionou em que região da lâmina foliar este caráter foi observado, dificultando a sua utilização nas comparações entre as espécies. As ilustrações apresentadas por Ciqiu et al. (1986) para o feixe vascular aberto corresponde a forma em arco, reconhecida no terço apical das cinco 
espécies de Maytenus estudadas.

O mesofilo das espécies estudadas apresentou conformação dorsiventral semelhante às encontradas nas espécies analisadas por P.M. Mendonça (dados não publicados). Metcalfe \& Chalk (1950) mencionaram a predominância de mesofilo dorsiventral na família Celastraceae, podendo ser isobilateral nos gêneros Gymnosporia e Maytenus. Ciqiu et al. (1986) atribuíram valores taxonômicos à forma do mesofilo e ao número de camadas do parênquima clorofiliano, pois não apresentaram variações com o ambiente. $\mathrm{O}$ número de camadas do parênquima paliçádico e do lacunoso pouco variou entre as espécies estudadas. As folhas coletadas na Floresta da Tijuca apresentaram a organização do parênquima lacunoso de maneira típica, ou seja, com grandes lacunas. Em M. obtusifolia, proveniente da restinga de Grumari, a lacunosidade é menos desenvolvida. Vieira (1995), analisando folhas de indivíduos de Bauhinia radiata Vell. em diferentes ambientes, apontou o grau de intensidade luminosa e a disponibilidade de água como os fatores responsáveis pela variação no desenvolvimento do parênquima assimilador.

O bordo de todas as espécies apresentou-se muito semelhante, diferindo apenas nos extratos subepidérmicos observados em $M$. obtusifolia. Segundo Carvalho-Okano (2005), as características do bordo são tradicionalmente utilizadas na taxonomia devido a sua ampla variação no gênero Maytenus, e sua relativa constância nas espécies.

Rao \& Das (1979) assinalam a presença de esclereídes polimórficos para o gênero Maytenus, corroborando com Metcalfe \& Chalk (1950) que observaram formas irregulares de esclereídes em diferentes gêneros de Celastraceae. No pecíolo de M. ardisiaefolia, M. brasiliensis, M. cestrifolia, $M$. communis e $M$. obtusifolia ocorreram braquiesclereídes isodiamétricos, assim como no mesofilo de M. ardisiaefolia. Esclereídes polimórficos foram reconhecidos apenas em M. obtusifolia. Esau (1977) e Dickson (2000) relacionam a quantidade de esclereídes na lâmina foliar com o grau de luminosidade que os espécimes estão expostos. Provavelmente, a presença de uma maior diversidade de tipos de esclereídes em $M$. obtusifolia esteja relacionada com o menor grau de sombreamento ao qual o espécime coletado está submetido, quando comparado as demais espécies analisadas. Este fato torna possível afirmar que a variação no número dos tipos de esclereídes seja um caráter que pode ser explorado na taxonomia, quando comparados com espécies que co-habitam ou que estejam vegetando em ambientes similares.

Nas espécies estudadas, as células encerrando compostos fenólicos ocorreram em diversas regiões da folha, sendo abundantes no córtex do pecíolo e nas células parenquimáticas do mesofilo. Idioblastos com compostos fenólicos foram citados por Metcalfe \& Chalk (1950), Ciqiu et al. (1986), van Wyk \& Archer (1987) e Müller (1995) para o gênero em questão. P.M. Mendonça (dados não publicados) apontou diferenças nos polifenóis e os reconheceu como uma importante ferramenta no auxílio a taxonomia e nas relações filogenéticas envolvendo as espécies de Maytenus.

As estruturas anatômicas observadas nas diversas partes da folha mostraram-se muito semelhantes nas espécies estudadas, sendo de valor taxonômico e de provável importância filogenética para o gênero Maytenus. A organização da epiderme e estratos subepidérmicos em $M$. obtusifolia, demonstrou ser um caráter diagnóstico importante na comparação com M. ardisiaefolia, e a ocorrência de cristais aciculares nas células epidérmicas de $M$. communis e de $M$. ardisiaefolia, que a separa de $M$. cestrifolia, que não apresenta cristais, apontaram a anatomia como uma importante ferramenta a ser explorada nos estudos taxonômicos das demais espécies do gênero. A observação e descrição das verrugas suberosas ('Cork Wart') na epiderme da lâmina foliar poderá contribuir para a taxonomia das Celastraceae.

\section{Agradecimento}

Os autores agradecem a todos os membros do Laboratório de Morfologia Vegetal (UFRJ); ao suporte financeiro da CAPES (Bolsa de Mestrado do primeiro Autor); ao apoio da Fundação Universitária José Bonifácio (FUJB).

\section{Referência bibliográficas}

Archer, R.H. 1992. A new species of Maytenus (Celastraceae) from southern Natal and Transkei. South African Journal of Botany 58(5): 393-396.

Archer, R.H. \& Van Wyk, A.E. 1997a. A taxonomic revision of Robsonodendron, a new genus in Cassinoideae (Celastraceae). South African Journal of Botany 63(3): 116-122.

Archer, R.H. \& Van Wyk, A.E. 1997b. A taxonomic revision of Cassine L. s. str. (Cassinoideae: Celastraceae). South African Journal of Botany 63(3): 146-157.

Archer, R.H. \& Van Wyk, A.E. 1998a. A taxonomic revision of Elaeodendron Jacq. (Cassinoideae: Celastraceae). South African Journal of Botany 64(2): 93-109. 
Archer, R.H. \& Van Wyk, A.E. 1998b. A taxonomic revision of Maurocenia (Celastraceae), a Western Cape monotypic endemic. Bothalia 28: 7-10.

Bass, P. 1975. Vegetative anatomy and the affinities of Aquifoliaceae, Sphenostemon, Phelline and Oncotheca. Blumea 22: 311-407.

Carlquist, S. 1961. Comparative Plant Anatomy. New York, Holt, Rinehart and Winston.

Carvalho-Okano, R.M. 1998. Novos sinônimos para espécies de Maytenus Mol. emend. Mol. (Celastraceae). Bradea 14(8): 73-76.

Carvalho-Okano, R.M. \& Leitão Filho, H.F. 2005. O gênero Maytenus Mol. emend. Mol. (Celastraceae) no Brasil extra-amazônico. In: M.S. Reis \& S.R. Silva. Conservação e uso sustentável de Espinheira Santa 1: 11-51.

Ciqiu, Z.; Yanhui, L.; Shiwang Z. \& Shenji P. 1986. Anatomy of leaves on 17 species and one variety of Maytenus in relation to classification. Acta Botanica Yunnanica 8(1): 53-59.

Cronquist, A. 1988. The Evolution and Classification of Flowering Plants. $2^{\text {nd }}$ ed. New York, The New York Botanical Garden.

Cuatrecasas, J. 1959. Studies in South American plants - V. Brittonia 11: 163-172.

Den Hartog, R.M. \& Baas, P. 1978. Epidermal characters of the Celastraceae sensu lato. Acta Botanica Neerlandica 27: 355-388.

Dickison, W.C. 2000. Integrative Plant Anatomy. San Diego, Harcourt Academic Press.

Esau, K. 1977. Anatomy of Seed Plants. New York, John Wiley \& Sons.

Hallé, N. 1981. Révision des Hippocrateae (Celastraceae): Les genre Pristimera Miers em Afrique et en Indonésie. Adansonia 3(1): 5-14.

Hallé, N. 1984. Révision des Hippocrateae (Celastraceae): 4. Les genres Simirestis et Arnicratea (gen. nov.). Adansonia 6(1): 3-17.

Hammel, B.E. 1997. Three new species of Celastraceae from Costa Rica, one disjunct from Mexico. Novon 7(2): 147-155.

Handro, O. 1968. Plantas novas da flora do Brasil II. Celastraceae. Loefgrenia 27: 1.

Herter, W.G. \& Legrand, D. 1936. Dos árboles nuevos del Uruguay, pertencientes al gênero Maytenus (Celastraceae). Revista Sudamericana de Botánica 3: 110-114.

Hichey, L.J. 1974. Classificacion de la Arquitetura de las Hajas de Dicotiledoneas. Boletin de la Sociedad Argentina de Botânica 16(1-2): 1-26.

Hou, D. 1955. A revision of the genus Celastrus. Annals of the Missouri Botanical Garden 42: 215-302.

Howard, R. 1979. The Petiole. In: C.R. Metcalfe \& L. Chalk. Anatomy of the Dicotyledons. Oxford, Clarendon Press, v. 1. 88-96.

Johansen, D.A. 1940. Plant microtechnique. New York, Mc. Graw-Hill Book Co. Inc.

Jordaan, M. \& Van Wyk, A.E. 1999a. Systematic studies in subfamily Celastroideae (Celastraceae) in southern Africa: reistatement of the genus Gymnosporia. South African Journal of Botany 65(2): 177-181.
Jordaan, M. \& Van Wyk, A.E 1999b. Systematic studies in subfamily Celastroideae (Celastraceae) in southern Africa: two new species of Gymnosporia from Maputaland Centre of Endemism. South African Journal of Botany 65(5/6): 177-181.

Judd, W.S.; Campbell, C.S.; Kellogg, E.A. \& Stevens, P.F. 1999. Plant Systematics: A Phylogenetic Approach. Massachusetts, Sinauer Associates.

Leite, J.P.V.; Rastrelli, L. \& Romussi, G. 2001. Isolation and HPLC quantitative analysis of flavonoid glycosides from Brazilian beverages (Maytenus ilicifolia and Maytenus aquifolium). Journal of Agricultural and Food Chemistry 49(8): 3796-3801.

Loesener, T. 1892. Celastraceae. Bleiblatt $\mathrm{zu}$ den Botanischen Jahrbuechern 15: 6-10.

Loesener, T. 1942. Celastraceae. In: A. Engler \& K. Prantl (eds.). Die Natürlichen Pflanzenfamilien 20b: 87-197.

Lourteig, A. \& O'donell, C.A. 1955. Las Celastraceas de Argentina y Chile. Natura 1: 181-233.

Machado, O. 1945. Contribuição ao estudo das plantas medicinais do Brasil: Maytenus obtusifolia Mart. Rodriguésia 9(18): 9-15.

Mayr, E. 1989. O desenvolvimento do pensamento biológico: diversidade, evolução e herança. Brasília, Universidade de Brasília.

Metcalfe, C.R. \& Chalk, L. 1950. Anatomy of the Dicotyledons. Oxford, Clarendon Press. v.2, 1500p.

Metcalfe, C.R. \& Chalk, L.1979. Anatomy of the Dicotyledons. $2^{\text {nd }}$ ed. Oxford, Clarendon Press. v.1, 276p.

Mossi A.J.; Cansian R.L. \& Carvalho A.Z. 2004. Extraction and characterization of volatile compounds in Maytenus ilicifolia, using high-pressure CO2. Fitoterapia 75(2): 168-178.

Müller, I.H. 1995. Systematics and leaf anatomy of the Celastraceae sensu stricto of New Caledonia. Doctoral dissertation. Zürich, Universität Zürich.

Niero, R.; Moser, R.; Busato, A.C.B.; Yunes, R.A.; Reis, A. \& Cechinel, V. 2001. A comparative chemical study of Maytenus ilicifolia Mart. Reiss and Maytenus robusta Reiss (Celastraceae). Zeitschrift fur Naturforschung C-A Journal of Biosciences 56(1-2): 158-161.

Pant, D.D. \& Kidwai, P.F. 1966. Epidermal structure and stomatal ontogeny in some Celastraceae. New Phytologist 65: 288-295.

Pirani, J.R. \& Carvalho-Okano, R.M. 1999. Maytenus rupestris (Celastraceae), a New Species from Minas Gerais, Southeastern Brazil. Novon 9(1): 95-97.

Rao, T.A. \& Das, S. 1979. Leaf sclereids - occurrence and distribution in the angiosperms. Botanic Notiser 132: 319-324.

Reissek, S. 1861. Celastrineae, Ilicineae, Rhamneae. In: C.F.P. Martius \& A.G. Eichler. Flora Brasiliensis 11(1): 1861-1879.

Rizzini, C.T. 1960/1961. Sistematização Terminológica de Folha. Rodriguésia 35/36: 193-208.

Roeser, K.R. 1962. Die Nadel der Schwarziefer - Massen produkt und Kunstwert der Natur. Mikrokosmos 61: 33-36. 
Ruzin, S.E. 1999. Plant Microtechnique and Microscopy New York, Oxford University Press.

Sass, J.E. 1951. Botanical Microtechnique. Iowa, The Iowa State College Press.

Sebsebe, D. 1985. The genus Maytenus (Celastraceae) in NE tropical Africa and tropical Arabia. Acta Universitatis Upsaliensis Symbolae Botanicae Upsaliensis 25(2): 1-101.

Simmons, M.P. \& Hedin, J.P. 1999. Relationships and morphological character change among genera of Celastraceae sensu lato (including Hippocrateaceae). Annals of the Missouri Botanical Garden 86: 723-757.

Simmons, M.P.; Clevinger, C.C.; Savolainen, V.; Archer, R.H.; Mathews, S. \& Doyle, J.J. 2001. Phylogeny of the Celastraceae inferred from phytochrome $B$ gene sequence and morphology. American Journal Botany 88(2): 313-325.

Smith, A.C. 1940. The American species of Hippocrateaceae. Brittonia 3: 341-555.
Solereder, H. 1908. Sistematic Anatomy of the Dicotyledons. Oxford, Clarendon Press. v.2.

Speer, E. O. 1987. A Method of retaining phloroglucinol proof of lignin. Stain Technology 62: 279-280.

Stace, C.A. 1965. Cuticular studies as an aid to plant taxonomy. Bulletin of the British Museum (Natural History) Botany 4: 1-78.

Strasburger, E. 1983. Handbook of practical Botany. London, Swan Sonnesnschein Co.

Strittmater, C.G.D. 1973. Nueva Tecnica de Diafanizacion. Boletin de la Sociedad Argentina de Botânica 15(1): 33-39.

Van Wyk, A.E. \& Archer, R.H. 1987. Maytenus oleosa (Celastraceae), a new species from southern Natal and Pondoland. South African Journal of Botany 53(2): 155-160.

Vieira, R.C. 1995. Anatomia da Folha de Bauhinia radiata Vell. em diferentes ambientes. Arquivo de Biologia e Tecnologia 38(1): 63-107. 